Surg Endosc (2004) 18: 1542

DOI: $10.1007 / \mathrm{s} 00464-004-0086-1$

(C) Springer Science+Business Media, Inc. 2004

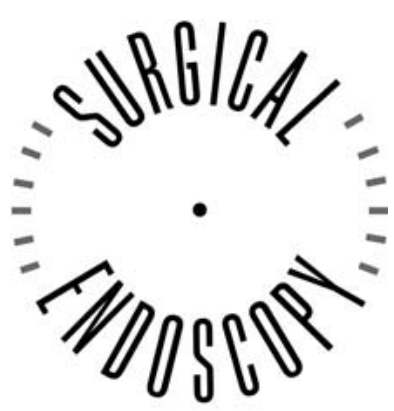

and Other Interventional Techniques

\title{
Laparoscopic adrenalectomy
}

Ascending the learning curve

\section{Goitein, Y. Mintz, D. Gross, P. Reissman}

Jerusalem, Israel

[Surg Endosc (2004) 18: 771-773, DOI: 10.1007/s00464-003-8830-5]

The corrected list of authors' names is printed here. 